\title{
Research and future trends in the pharmaceutical development of medicinal herbs from Chinese medicine
}

\author{
Kuo-Hsiung Lee* \\ Natural Products Laboratory, School of Pharmacy, University of North Carolina at Chapel Hill, Chapel Hill, \\ NC 27599-7360, USA
}

\begin{abstract}
Issues concerning the past and future development of medicinal herbs from Chinese medicine (CM) are addressed in this paper. In the Western world, medicinal herbs are becoming increasingly popular and important in the public and scientific communities. In contrast to their regulated status in China and other countries, herbal medicines are regarded as dietary supplements in the US. Accordingly, research must continue worldwide to identify and improve the efficacy of the active principals of herbs both singly and in combination - from active ingredients, active fractions, and active herbal formulations. While Western medicine currently employs pure, single compounds, either natural or synthetic, CM has long used multiple combinations of compounds in the form of processed natural products, primarily medicinal herbs, to treat and relieve the symptoms of many different human diseases. CM may have fewer and less severe side effects than single pure drugs, making CM especially attractive to the consumer. In effect, CM's focus on combination therapy does serve both ancient and modern theories. However, research using modern analytical and chemical techniques is needed to ensure efficacy and safety, to provide qualitative and quantitative analyses for dietary supplements, and to develop new, effective and safe world-class drugs. Drug design is an iterative process. Bioactivity-directed fractionation and isolation identify active natural compounds from single herbs or formulations. These lead structures can be chemically modified and improved through knowledge of structure-activity relationship, mechanism of action, drug metabolism, molecular modelling and combinatorial chemistry studies. Finally, efficacy and toxicity determination as well as clinical trials can contribute to the generation of new drugs from CM. To continue the legacy of CM, as well as the worldwide uses of other medicinal herbs, continued investigation of active formulations, bioactive fractions, and isolated compounds is critical to drug development in the 21st century.
\end{abstract}

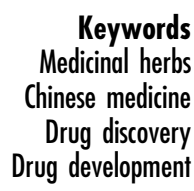

Medicinal herbs, including those used in Chinese Medicine (CM), are being accepted and used increasingly by the general population, studied rigorously by scientists in academia and industry, and manufactured internationally. The focus of herbal medicine on the patient rather than the disease is appealing to consumers. Chronic and age-related diseases (including antioxidant and antiaging, blood pressure-lowering, hypolipidemic, blood sugar-lowering, anti-allergic, and anti-arthritic effects), disease prevention and health maintenance are particularly attractive targets. Examples of some of the medicinal herbs used widely in the US and Europe include comfrey (Symphytum officinale), echinacea (Echinacea purpurea), feverfew (Tanacetum parthenium), garlic (Allium sativum), ginkgo (Ginkgo biloba), ginseng (Panax ginseng), saw palmetto (Serena repens) and St. John's wort (Hypericum perforatum) ${ }^{1}$.

With this increasing popularity also comes the need for competent monitoring and scientific research to maintain quality assurance (QA) or control (QC) of botanical, chemical, manufacturing, biological, and clinical aspects in order to guarantee value, safety, and efficacy of herbal products. In the US, herbal medicines are dietary supplements. Thus, to address the growing need for consumer information and protection and to promote good manufacturing practices (GMP) standards, independent testing programmes, such as the Natural Nutrition \& Foods Association (NNFA) and the online (ConsumerLab.com $\rangle$, have been established recently. Both programmes have registration or approval standards and use 
physical and analytical testing technologies to monitor herbal products ${ }^{\dagger}$. In their independent tests, these organizations have found many marketed manufactured herbals, such as ginkgo and saw palmetto, to be insufficient in selected marker compounds. Clearly, QA/QC and monitoring must be improved diligently to promote the safe use of herbal products.

Herbs have been used as folk medicines from mankind's beginnings and also have been the source of many 'modern' single drugs. In the current practice of drug discovery, a herb or herbal prescription is targeted from folk or clinical experiences. Extraction of the target herbal medicine results in the most promising new active natural products or their synthetic analogues through verified pharmacological testing and bioactivity-directed fractionation and isolation (BDFI) of active portions. The ultimate drug candidates enter the next stage of drug design, which is drug development. At this step, efficacy and toxicity are determined and production, formulation, and toxicological studies are performed. Clinical trials are the ultimate logical goal of these preclinical steps.

However, the multi-component and synergistic nature of $\mathrm{CM}$ should not be ignored. In future drug discovery and development, research must continue worldwide to identify and improve the efficacy of herbal active principals both singly and in combination from active ingredients, active fractions, and active prescriptions of herbal formulations.

\section{Overview of Chinese medicine}

Several reviews of Chinese medicinal plant-derived chemotherapeutic agents have been published ${ }^{2-8}$. CM is based on a long tradition of herbal medicine. Both single herbs, such as ginseng, ginkgo (Ying-Shin), ephedra (Ma-Huang), apricot seed (Xin-Jen), and licorice (Gan-Tsao), and more often, multi-component herbal formulations, such as $\mathrm{Ma}$ Xin Shi Gan Tang (Ma-Huang \& Xin-Jen Combination) have been used medicinally since antiquity. All Chinese medicinals are derived from natural products, with more than 80\% from plants. Folk drugs (Min Chien Yao) and about 500 commonly prescribed Chinese traditional drugs (Chung Yao) ${ }^{9}$, derived from about 5000 plant species with identified therapeutic value, are used according to a series of systemic and self-contained theories in order to relieve and cure many different human diseases and health conditions. CM has undergone thousands of years of accumulated human trials and remains today a unique, fundamental foundation for modern drug discovery and development.

Chinese and Western medicines have both contributed greatly to health and disease treatment, but each has formed its own fundamental rules. These rules make the

\footnotetext{
${ }^{\dagger}$ This information is presented to indicate the need for standardization and QC of herbal products. These agencies have developed their own methodologies, which does not negate the need for further validation and research efforts.
}

two quite different, in practice and in theory, especially in the drugs they design and use. Western medicine uses pure natural or synthetic compounds aimed at a single target, while CM uses processed crude multi-component natural products - in various combinations and formulations aimed at multiple targets - to treat a totality of different symptoms. Specific CM treatments are chosen based on careful diagnostic observations and systematic principles. The three most common treatment principles are mobilization of blood circulation and treatment of statis, promotion of vigour and stabilization of vitality, and treatment of fever and inflammation along with detoxification? ${ }^{\text {. Terminolo- }}$ gies such as bodily energy or qi, yin/yang, and coolness/ heat are central to $\mathrm{CM}$ and establishing an optimum balance of such forces is considered important to promote health ${ }^{10}$.

Thousands of herbal formulations (consisting of four to 12 individual herbs, in general) have been recorded in Chinese medical literature from the earliest known 'Shen Nung Ben Tsao Jing' to the more contemporary Chinese Materia Medica ${ }^{9,10}$. Chinese herbal pharmacology studies the composition, actions, indications, dosages, and clinical uses of herbal formulations. The herbal components can be ranked into four types ${ }^{10}$. The effectiveness of the principal herb is aided by the supporting herbs:

- imperial herb - the chief herb (main ingredient) of a formula

- ministerial herb - ancillary to the imperial herb, it augments and promotes the action of the former

- assistant herb - reduces the side effects of the chief herb

- servant herb - harmonizes or coordinates the actions of the other herbs

In the four-herb combinations shown in Table 1, the change in composition (one different and three identical ingredients, different proportions and different imperial/ ministerial herbs) induces different pharmacological actions $^{11}$.

\section{Modernization of $\mathbf{C M}$}

Modern technologies being used or under development for the QC of CM include: microscopic analyses (morphological investigation and powder methods), chromatographic methods for fingerprint profiling [thin-layer chromatography, high-performance liquid chromatography, liquid chromatography and gas chromatography (TLC, HPLC, LC, GC), GC- and LC-mass spectrometry (GC-MS and LCMS), LC/MS/MS and capillary electrophoresis (CE)], DNA polymorphism methods to analyse DNA sequences and establish relationships between genomic DNA fragment patterns and ratios of active components, and biological methods or bioassays. Modern instrumental quantification, identification, and comparison have been documented increasingly, for example, for licorice (by HPLC ${ }^{12}$ ), ginseng 
Table 1 Herbal formulations: comparison of composition and action

\begin{tabular}{lcccccc}
\hline & \multicolumn{5}{c}{ Single herb (ratio) } \\
\cline { 2 - 5 } Herbal formula & Ma-Huang & Licorice & Apricot seed & Cinnamon & Gypsum & Action \\
\hline Ma-Huang Combination & 5 & 1.5 & 5 & 4 & - & Induces sweating and \\
suppresses coughing \\
Herb ranking & $\mathrm{I}$ & $\mathrm{S}$ & $\mathrm{A}$ & $\mathrm{M}$ & \\
Ma-Huang \& Apricot Seed Combination & 4 & 2 & 4 & - & 10 & Suppresses sweating and \\
Herb ranking & $\mathrm{M}$ & $\mathrm{S}$ & $\mathrm{A}$ & $\mathrm{I}$ & coughing \\
\hline
\end{tabular}

I, imperial herb; M, ministerial herb; S, servant herb; $A$, assistant herb.

(by positive ion $\mathrm{MS}^{13}$ ) and Uncariae powder (Gou-TengSan) (by 3D-HPLC ${ }^{14,15}$ ). The latter prescription is used in exceptionally nervous patients, who exhibit, among various symptoms, insomnia (Shu-Wei Hsu's 'Pen Shih Fang', Sung Dynasty) and vascular dementia ${ }^{14}$.

Such technical modernization of CM is crucial to promote standardization and establish QC through qualitative and quantitative analysis of active constituents and bioactivity. In addition, efforts should be made to guarantee safety by evaluation of toxicity and side effects and to ensure efficacy based on clinical scientific observation, including doubleblind clinical trials, rather than anecdotal evidence only. Similarly, dietary supplements must meet all high quality assurance standards.

Modern analytical and pharmacological methods are being used to research and document the properties (not only the quantitative composition, but also the pharmacological action) of herbal formulations in comparison with their individual components. For example, over a 3-hour time course, the anti-tussive activity of the original fourcomponent prescription of Ma-Huang \& Xin-Jen Combination was reported to be greater than that of either Ma-Huang alone or of any two of the remaining ingredients 9 . The following three approaches for the development of new, effective and safe world-class drugs can be envisioned.
- Active principals (bioactive compounds) approach

- Active fractions approach

- Active formulations approach

Figure 1 illustrates graphically that, now and in the future, not only bioactive principals (lead compounds or leads), but also active fractions and active formulations, must be investigated to continue the legacy of CM, as well as the uses of other medicinal herbs, for drug development in the 21 st century.

\section{Current drug development process based on CM research}

Prior to clinical trials, the two main preclinical stages of drug design are drug discovery and drug development. The first stage is an iterative process of (1) lead discovery through bioactivity-directed fractionation and isolation (BDFI) of natural bioactive lead compounds from single herbs, extract fractions, or herbal prescriptions and (2) lead improvement through chemical modification and synthesis of improved analogues. The rational design of synthetic analogues uses (a) structure-activity relationship (SAR) studies to evaluate qualitative and quantitative SAR, (b) mechanism of action studies to study drug-receptor interactions and specific enzyme inhibition, (c) drug

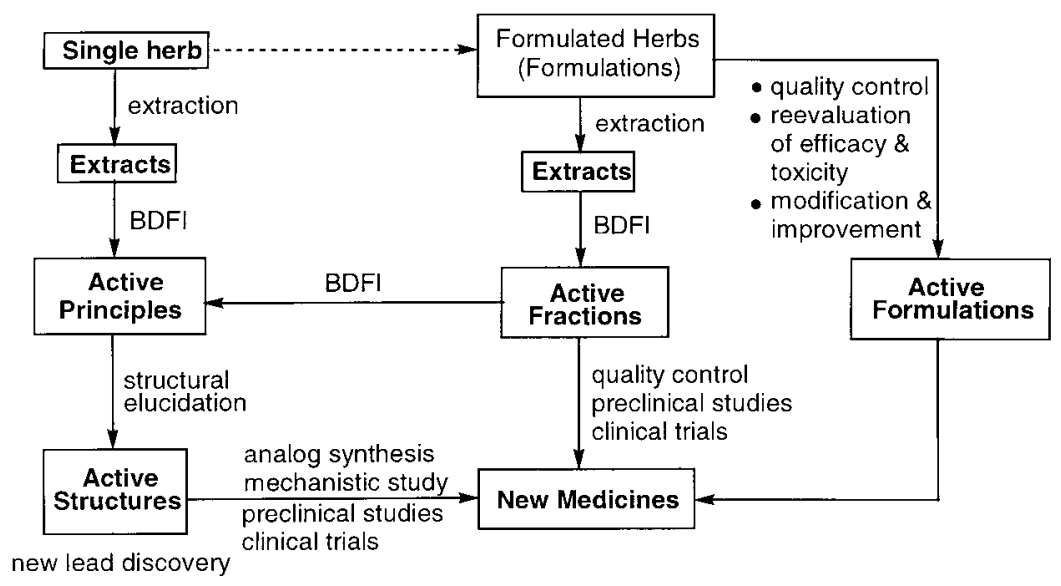

Fig. 1 Principal concepts of research on new medicinals 
Table 2 Chemotherapeutic agents from Chinese medicine

\begin{tabular}{|c|c|c|c|}
\hline Disease/drug & Chinese formulation; natural source & Comments & Reference \\
\hline $\begin{array}{l}\text { Chronic myelocytic leukemia } \\
\text { Indirubin and its } \\
\text { methylated analogues }\end{array}$ & $\begin{array}{l}\text { 'Dang Gui Lu Hui'; } \\
\text { Indigo naturalis }\end{array}$ & & 16,17 \\
\hline $\begin{array}{l}\text { Malaria } \\
\text { Artemisinin and its } \\
\text { synthetic derivatives } \\
\text { including artemether }\end{array}$ & $\begin{array}{l}\text { 'Qing Hao'; } \\
\text { Artemisia annua }\end{array}$ & $\begin{array}{l}\text { Latter compound is in clinical use } \\
\text { in China and in Phase II clinical } \\
\text { trials in the US }\end{array}$ & $18-20$ \\
\hline $\begin{array}{l}\text { Various cancers } \\
\text { Camptothecin }\end{array}$ & $\begin{array}{l}\text { Camptotheca acuminata } \\
\text { (Han Lien) }\end{array}$ & $\begin{array}{l}\text { Natural alkaloid is a potent DNA } \\
\text { topoisomerase I (topo I) inhibitor. } \\
\text { Used to treat gastric, rectal, } \\
\text { colon, and bladder cancers }\end{array}$ & 21 \\
\hline $\begin{array}{l}\text { 9-Amino and 10-hydroxy } \\
\text { camptothecin, topotecan, } \\
\text { and irinotecan } \\
\text { 7-(Acylhydrozono)-formyl } \\
\text { camptothecins }\end{array}$ & & $\begin{array}{l}\text { Natural and synthetic derivatives } \\
\text { of camptothecin } \\
\text { Water-soluble compounds } \\
\text { synthesized to combat poor water } \\
\text { solubility of camptothecin. } \\
\text { Compound with a 7-(L-tyrosylhydrazono) } \\
\text { group was more potent than } \\
\text { camptothecin in causing protein-linked } \\
\text { DNA breaks and in inhibiting DNA topo I; } \\
\text { however, it was less toxic in several } \\
\text { cancer cell lines }\end{array}$ & $22-26$ \\
\hline $\begin{array}{l}\text { Hepatitis } \\
\text { DDB, synthetic analogue of } \\
\text { natural schizandrin C }\end{array}$ & Schizandra species & $\begin{array}{l}\text { Used in China to treat a chronic and } \\
\text { persistent form of hepatitis }\end{array}$ & 28 \\
\hline $\begin{array}{l}\text { Nervous system disorders } \\
\text { Huperzine A }\end{array}$ & Huperzia serrata & $\begin{array}{l}\text { Used in } \mathrm{CM} \text { to treat mental disorders. } \\
\text { Potent reversible cholinesterase inhibitor. } \\
\text { Improves learning, facilitates memory } \\
\text { retrieval. } 99 \% \text { effectiveness rate in treating } \\
128 \text { patients with myasthenia gravis }\end{array}$ & 29 \\
\hline $\begin{array}{l}\text { Encephalomyelitis, toxic dyse } \\
\text { Anisodamine }\end{array}$ & $\begin{array}{l}\text { ry, and Meniere's disease } \\
\text { Anisodus tanguticus }\end{array}$ & $\begin{array}{l}\text { Used in China to treat pain and functions } \\
\text { as a cholinergic blocking agent with low toxicity }\end{array}$ & 30,31 \\
\hline $\begin{array}{l}\text { Glaucoma } \\
\text { Baogongteng A }\end{array}$ & $\begin{array}{l}\text { 'Ding Gong Teng'; } \\
\text { Erycibe obtusifolia }\end{array}$ & Tropane alkaloid; strong myotic agent & 32,33 \\
\hline $\begin{array}{l}\text { Fertility regulation } \\
\text { Yuanhuacin }\end{array}$ & $\begin{array}{l}\text { 'Yuan Hua'; } \\
\text { Daphne genkwa }\end{array}$ & $\begin{array}{l}\text { Augments uterine contractions. } \\
\text { Used clinically with few side effects } \\
\text { to induce abortion. Also has antileukemic properties }\end{array}$ & $34-36$ \\
\hline $\begin{array}{l}\text { Heart disease } \\
\text { Tanshinone IIA }\end{array}$ & Salvia miltiorrhiza & & 37 \\
\hline
\end{tabular}

metabolism studies to determine bioactive metabolites or block metabolic deactivation, (d) molecular modelling studies to determine 3D pharmacophores, and (e) combinatorial chemistry studies to generate leads by the creation of chemical libraries. The goals are to improve pharmacological profiles by increasing activity, decreasing toxicity, or circumventing metabolic, pharmacokinetic, solubility, or drug-resistance problems. The examples in the next section illustrate the diversity, rationale, and power of these processes.

\section{Examples of known and developing drug agents from CM: including from the author's Natural Products Laboratory (NPL)}

As early as 1882, investigation of CM led to the discovery of ephedrine from Ephedra sinica (Ma-Huang). This compound and its numerous synthetic analogues are used today as effective anti-asthma agents. Table 2 shows other drugs generated by research on CM for other diseases and disorders $^{16-37}$.

The preclinical development of bioactive natural products and their analogues as chemotherapeutic agents is a major objective of the NPL. Current research programmes at the NPL include the following.

1. Plant anti-tumour agents - novel plant-derived cytotoxic anti-tumour principals and analogues.

2. Novel anti-tumour etoposide analogues - design and synthesis of novel analogues related to the anti-cancer drug etoposide with better pharmacological profiles as described below for GL331 (Fig. 2).

3. Development of anti-AIDS agents - plant-derived anti- 
<smiles>COc1cc([C@H]2c3cc4c(cc3[C@@H](Nc3ccc([N+](=O)[O-])cc3)[C@H]3COC(=O)[C@H]23)OCO4)cc(OC)c1O</smiles>

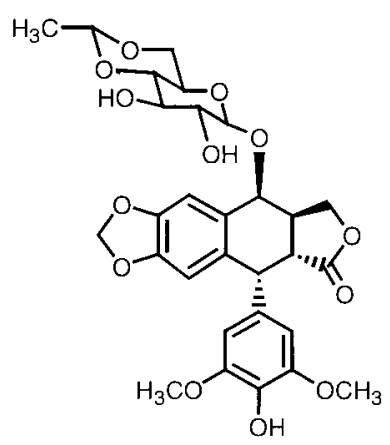

Etoposide<smiles>COc1cc([C@H]2c3cc4c(cc3[C@@H](O)[C@@H]3COC(=O)[C@@H]23)OCO4)cc(OC)c1OC</smiles>

Podophyllotoxin (Podophyllum peltatum, $P$. emodi)

Fig. 2 GL33, an anti-cancer lead compound in development at the NPL, and its synthetic and natural lead compounds

HIV compounds. Two classes of modified natural products [triterpene derivatives DSB and DSD, developed from betulinic acid (Szyigium claviflorum) and the coumarin derivative DCK, developed from suksdorfin [Lomatium suksdorfii or Angelica morii (Shan Du Huo)]] are under development as clinical trials candidates (Fig. $3)^{38}$.

4. Novel anti-malarial agents - anti-malarial analogues related to qinghaosu.

5. Anti-viral hepatitic drugs - design and synthesis of analogues related to DDB, a clinically useful anti-viral hepatitic drug (see Table 2) and other new leads.

6. New non-steroidal anti-inflammatory and anti-arthritis agents.

7. New anti-fungal agents.

8. Novel anti-viral agents - inhibitors of HSV I and II and HCMV.

9. Combinatorial chemistry - focused combinatorial libraries based on bioactive natural products models.

10. Chinese medicines - discovery and development of active principals, fractions, and formulations from traditional Chinese herbal medicines.

In the area of anti-cancer drug design, the NPL has discovered more than 1000 new cytotoxic anti-tumour principals and their derivatives or synthetic analogues from medicinal herbs in the past nearly three decades. Cytotoxic extracts, fractions and compounds are screened first in an initial in-house human tumour cell line (HTCL) panel and then followed through BDFI, focusing on one or two of the most active bioassays systems. Promising samples are confirmed active by evaluation in National Cancer Institute (NCI) in vitro HTCL and in vivo xenograft assays ${ }^{39}$. In this manner, bioactivity- and mechanism-directed fractionation and isolation of Chinese medicinal herbs, coupled with rational structural modification and synthesis, have resulted in more than 100 new cytotoxic anti-tumour compounds and their analogues that are of current interest to NCI and have shown confirmed activity in NCI's in vitro primary human tumour cell lines bioassay ${ }^{40}$.

The success of this process is illustrated by the development of the epipodophyllotoxin derivative GL331 (Fig. 2) from a natural product model. Etoposide is a semisynthetic derivative of the natural product podophyllotoxin, which is isolated from Podophyllum peltatum or $P$. emodi (Xi Zhang Guei Chiu) (Fig. 2). However, their differences include both structural changes at the 4 - and $4^{\prime}$ position and their mechanism of action: podophyllotoxin targets tubulin, while etoposide targets the enzyme DNA topo $\mathrm{II}^{41}$. Etoposide and the related thiophene analogue teniposide are widely used to treat various cancers, including leukaemias and lymphomas; however, myelosuppression, drug resistance, and poor bioavailability remain problems associated with their use ${ }^{42-44}$.

Using cytotoxicity and enzyme inhibition assays coupled with computer modelling studies, the NPL developed 

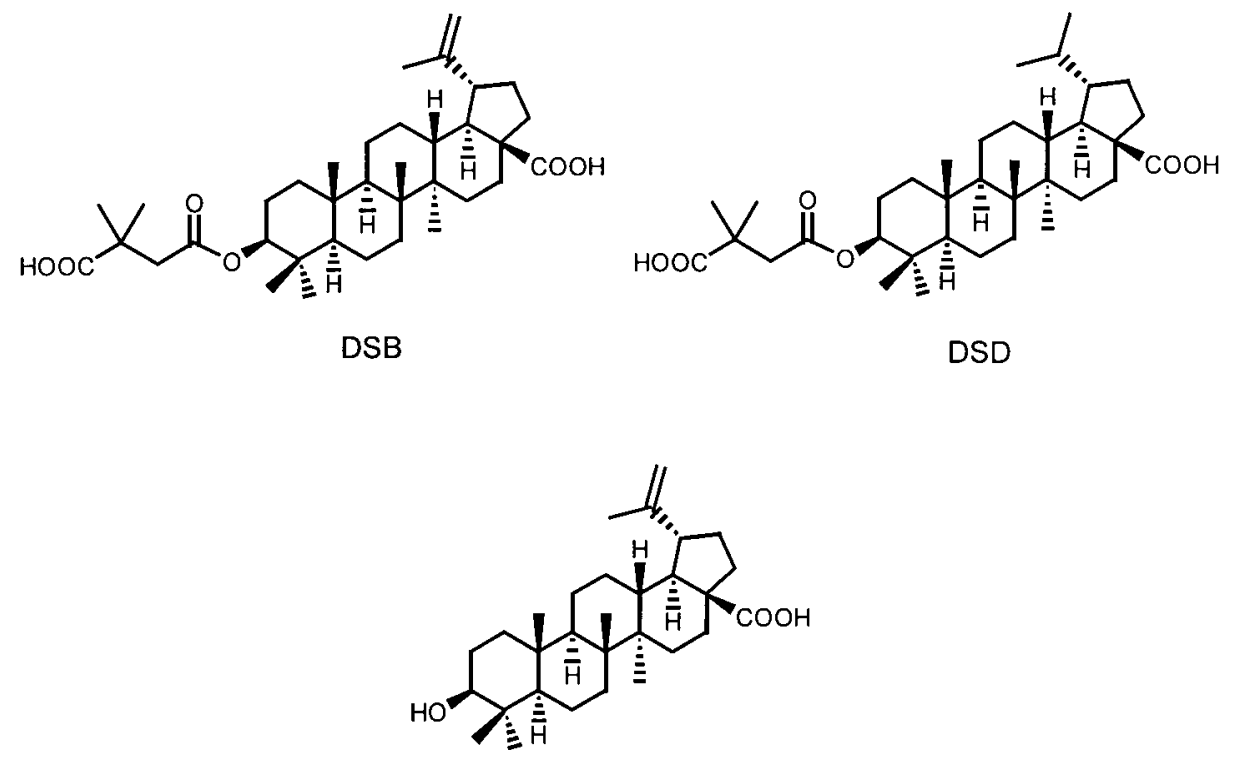

Betulinic Acid (Szyigium claviflorum)

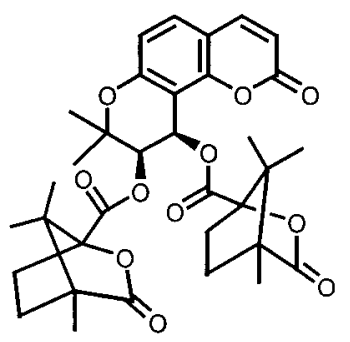

DCK<smiles>CC(=O)O[C@H]1c2c(ccc3ccc(=O)oc23)OC(C)(C)[C@H]1OC(=O)CC(C)C</smiles>

Suksdorfin (Lomatium suksdorfii)

Fig. 3 Structures of anti-HIV natural lead compounds and their synthetic analogues in development at the NPL

several series of active analogues, including 4-alkylamino and 4-arylamino epipodophyllotoxin analogues, such as GL331 ${ }^{45}$. GL331, which contains a p-nitroanilino moiety at the $4 \beta$ position of $4^{\prime}$-demethyl-epipodophyllotoxin, has emerged as an excellent drug candidate from the anti-cancer programme at the NPL. GL331 was patented by Genelabs Technologies, Inc., has completed successful Phase I clinical trials as an anti-cancer drug at the M.D. Anderson Cancer Center, and currently is in Phase II clinical trials against various cancers ${ }^{46}$. GL331 showed marked anti-tumour efficacy in four tumour types (nonsmall and small cell lung, colon, and head/neck cancers), minimal side effects, and an MTD of $300 \mathrm{mg} \mathrm{m}^{-2}$. Formulated GL331 shows desirable stability and biocompatability and good pharmacokinetic profiles. GL331 and etoposide both function as topo II inhibitors; however, GL331 is more active both in vitro and in vivo, is synthesized and, therefore, potentially manufactured in fewer steps, and can overcome multi-drug resistance in etoposide-resistant variant cancer cell lines. Overall, GL331 is an exciting new chemotherapeutic candidate. Much of this work on the development of GL331 and other topoisomerase inhibitors as anti-tumour agents has been reviewed ${ }^{47}$.

\section{New trends and technologies in CM research}

Chinese medicinals are being studied increasingly as multicomponent entities as well as through their individual active components. For example, the eight-herb formulation 'Hsiao Ching Long Tang' (Minor Blue Dragon Combination) was found to inhibit the Epstein-Barr virus early antigen (EBV-EA) activation induced by 12-O-tetradecanoylphorbol13-acetate (TPA ${ }^{48}$. Also, two lignans, asarinin and xanthoxylol, isolated from a single herbal component, inhibited carcinogenesis in mouse skin and pulmonary tumours ${ }^{49}$. Chinese formulations are also being viewed not only as sources of single drugs, but as therapeutic tools themselves. 
Formulations and extracts ${ }^{50-52}$ have been used to treat hepatitis (Ku Huang injection), brain disease (Deng Zhan Xi Xin injection), and cardiovascular disease (Di Ao Xin Xue Kang tablet and Su Xiao Chiu Xing pill). In addition, modern tissue culture methods can produce active CM principals such as ginseng and shikonin (used for burns, inflammation and wounds, and also in cosmetics) ${ }^{53-55}$ in large quantities over a period of several months. Finally, controlled clinical trials of $\mathrm{CM}^{56,57}$ have been documented in Western medical journals, as has the validity of synergy between components of a medicinal plant ${ }^{58}$.

\section{Conclusions}

$\mathrm{CM}$ will continue to provide a broad base for the discovery of new drugs, not only from bioactive lead compounds, but also from active fractions and active formulations. Highly efficient bioactivity-directed fractionation and isolation, structure characterization, analogue synthesis and mechanistic studies will provide the process by which new single compounds and active fractions can be developed as clinical candidates.

The safety and efficacy of single herbs and of multicomponent prescriptions must be verified and ensured by reliable pharmacological and toxicological methods and standards and by clinical trials.

Modern technology must be applied to establish quality controls and standardize herbal products using biological and chemical markers.

In summary, new drug discovery and development from CM should proceed through three approaches: pure active principals, active fractions, and validated or improved formulations.

\section{Acknowledgement}

The author thanks Dr. Susan L. Morris-Natschke for editorial assistance in preparation of this manuscript, and support in part from NIH grants CA 17625 (National Cancer Institute) and AI 33066 (National Institute of Allergies and Infectious Diseases).

\section{References}

1 Foster S, Tyler VE. Tyler's Honest Herbal: A Sensible Guide to the Use of Herbs and Related Remedies, fourth edition. New York: The Haworth Herbal Press, 1999: 121: 143: 161: 272: 183: 331: 343.

2 Lee KH. Antineoplastic agents from Chinese traditional medicine and their analogs. In: Kinghorn AD, Balandrin $\mathrm{M}$, eds. Human Medicinal Agents from Plants. American Chemical Society Symposium Series 534. Washington, DC: American Chemical Society/CRC Press; 1993: 170-90.

3 Lee KH. Scientific Chinese herbal medicine: research and movements toward worldwide acceptance. J. Food Drug Anal. 1997; 5: 233-4.

4 Lee KH. Recent new drugs discovered and developed from Chinese medicine. Biopharma Q. 1998; 4: 12-15.
5 Lee KH. Antitumor agents 195. Anticancer drug design based on plant-derived natural products. J. Biomed. Sci. 1999; 6: 236-50.

6 Lee KH. Antitumor agents 188. Highlights of research on plantderived natural products and their analogs with antitumor, anti-HIV, and antifungal activity. In: Cutler SJ, Cutler HG, eds. Biologically Active Natural Products. Washington, DC: American Chemical Society/CRC Press, 1999: 73-94.

7 Lee KH. Antitumor agents 197. Novel antitumor agents from higher plants. Med. Res. Rev. 1999; 19: 569-96.

8 Wang HK, Lee KH. Antitumor agents 176. Plant-derived anticancer agents and their analogs currently in clinical use or in clinical trials. Bot. Bull. Acad. Sin. 1997; 38: 225-35.

9 Hosoya E. The pharmacology of kampo prescriptions. In: Takemi T, Hasegawa M, Kumagai A, Otsuka Y, eds. Herbal Medicine: Kampo, Past and Present. Tokyo: Life Science Publishing Co., 1985: 52-65.

10 Huang KC. The Pharmacology of Chinese Herbs. Boca Raton, FL: CRC Press, 1993: 3-7.

11 Hsu HY. An Introduction to Chinese Medicine (Chung Kuo Yi Yao Gai Lun). Committee on Chinese Medicine. Taipei, Taiwan: The Executive Yuan Press, 1973: 48.

12 Shibata S. Qualification of extract-preparations of Chinese drug prescriptions. In: Takemi $\mathrm{T}$, Hasegawa $\mathrm{M}$, Kumagai A, Otsuka Y, eds. Herbal Medicine: Kampo, Past and Present. Tokyo: Life Science Publishing Co., 1985: 24-40.

13 Wang X, Sakuma T, Asafu-Adjaye E, Shiu GK. Determination of ginsenosides in plant extracts from Panax ginseng and Panax quinquefolius L. by LC/MS/MS. Anal. Chem. 1999; 71: 157984.

14 Terasawa K, Shimada Y, Kita T, Yamamoto T, Tosa H, Tanaka $\mathrm{N}$, et al. Choto-san in the treatment of vascular dementia. Phytomedicine 1997; 4: 15-22.

15 Sakakibara I, Takahashi H, Terabayashi S, Yuzurihara M, Kuba $\mathrm{M}$, Ishige A, et al. Effect of oxindole alkaloids from the hooks of Uncaria macrophylla on thiopental-induced hypnosis. Phytomedicine 1998; 5: 83-6.

16 Xiao PG. Traditional experience of Chinese herb medicine, its application in drug research and new drug searching. In: Beal JL, Reihard E, eds. Natural Products as Medicinal Agents. Stuttgart: Hippokrates Verlag, 1981: 351-94.

17 Zeng Q, Du D, Xie D, et al. Antitumor activities of indirubin derivatives. Chin. Trad. Herb Drugs 1982; 13: 24-30.

18 Imakura Y, Yokoi T, Yamagishi T, Koyama J, Hu H, McPhail AT. Antimalarial agents 5. Synthesis of desethanoquinghaosu, a novel analogue of the antimalarial qinghaosu. J. Chem. Soc. Chem. Commun. 1988; 5: 372-5.

19 Imakura Y, Hachiya K, Ikemoto T, Kobayashi S, Yamashita S, Sakakibara J, et al. Antimalarial artemisinin analogs: synthesis of 2,3-desethano-12-deoxoartemisinin-related compounds. Heterocycles 1990; 31: 2125-9.

20 Imakura Y, Hachiya K, Ikemoto T, Yamashita S, Kihara M, Kobayashi S. Acid degradation products of qinghaosu and their structure-activity relationships. Heterocycles 1990; 31: 1011-6.

21 Wall ME, Wani MC, Cook CE, Palmer KH, McPhail AT, Sim GA. Plant antitumor agents. I. The isolation and structure of camptothecin, a novel alkaloidal leukemia and tumor inhibitor from Camptotheca acuminta. J. Am. Chem. Soc. 1966; 88: 3888-90.

22 Wani MC, Nicholas AW, Wall ME. Plant antitumor agents. 23. Synthesis and antileukemic activity of camptothecin analogues. J. Med. Chem. 1986; 29 (11): 2358-63.

23 Johnson RK, McCabe FL, Faucette LF, Hertzberg RP, Kingsbury WD, Boehm JC, et al. SK\&F 104864, a water-soluble analog of camptothecin with broad spectrum activity in preclinical tumor models. Proc. Am. Assoc. Cancer Res. 1989; 30: 623.

24 Burris HA, Fields SM, Kuhn JG, Von Hoff DD. Camptothecins: dose-limiting toxicities and their management. In: Potmesil M, Pinedo H, eds. Camptothecins: New Anticancer Agents. Boca Raton, FL: CRC Press, 1995: 113-21. 
25 Negoro S, Fukuoka M, Masuda N, Takada M, Kusunoki Y, Matsui K, et al. Phase I study of weekly intravenous infusions of CPT-11, a new derivative of camptothecin, in the treatment of advanced non-small-cell lung cancer. J. Natl. Cancer Inst. 1991; 83 (16): 1164-8.

26 Kawato Y, Aonuma M, Hirota Y, Kuga H, Sato K. Intracellular roles of $\mathrm{SN}-38$, a metabolite of the camptothecin derivative CPT-11, in the antitumor effect of CPT-11. Cancer Res. 1991; 51 (16): 4187-91.

27 Wang HK, Liu SY, Hwang KM, Taylor G, Lee KH. Antitumor agents 153. Synthesis of novel water-soluble 7-(aminoacylhydrazono)-formyl camptothecins with potent inhibition of DNA topoisomerase I. Bioorg. Med. Chem. 1994; 2: 1397-403.

28 Liu GT. From the study of Fructus schizandrae to the discovery of biphenyl-dimethyl-dicarboxylate. Acta Pharm. Sin. 1983; 18: 714-20.

29 Liu JS, Zhu YL, Yu CM, Zhou YZ, Han YY, Wu FW, et al. The structures of huperzines $\mathrm{A}$ and $\mathrm{B}$, two new alkaloids exhibiting marked anti-cholinesterase activity. Can. J. Chem. 1986; 64: 837-9.

30 Han YF, Chen XY. Effects of anisodine and other cholinergic drugs on conditioned response of the hippocampal theta rhythm in rabbits. Acta Pharmacol. Sin. 1984; 5: 166-70.

31 Peng JZ, Chen ZX, Chen XY. Effects of anisodine on EEG and behavior of cats. Acta Pharmacol. Sin. 1982; 3: 78-81.

32 Yao TR, Chen ZN. Chemical studies on Erycibe obtusfolia. Bao Gong Teng. I: Isolation and preliminary study on a new myotic constituent Bao Gong Teng A. Yaoxue Xuebao 1979; 14: 7314; Chem. Abstr. 1980; 93: 101406n.

33 Xiang Z, Zhou JE, Chen ZN, Wang LP, Wang HN, Yao TR, et al. Studies on synthesis of baogongteng A - a new myotic agent. Yao Hsueh Hsueh Pao 1989; 24: 105-9.

34 Wang CR, Huang HZ, Xu RS. Studies on the active principals of the root yuan-hua. Isolation and structure of yuan hua fine. Acta Chim. Sin. 1982; 40: 835-9.

35 Wang WC, Shen S. Effects of yuanhuacine and yuanhuadine on in vitro uterine contraction in rat. Reprod. Contraception 1988; 8: $60-1$

36 Liou YF, Hall IH, Lee KH. Antitumor agents 56: The protein synthesis inhibition by genkwadaphnin and yuanhuacine of P388 lymphocytic leukemia cells. J. Pharm. Sci. 1982; 71: 13404 .

37 Yagi A, Fujimoto K, Tanonaka K, Hirai K, Takeo S. Possible active components of tan-shen (Salvia miltiorrbiza) for protection of the myocardium against ischemia-induced derangements. Planta Med. 1989; 55: 51-4.

38 Lee KH, Morris-Natschke SL. Recent advances in the discovery and development of plant-derived natural products and their analogs as anti-HIV agents. Pure Appl. Chem. 1999; 71: 104551.

39 Boyd MR. In: Neiderhuber JE, ed. Current Therapy in Oncology. Philadelphia, PA: BC Decker, 1993: 11-22.

40 Personal communications with Drs. D Lednicer, VL Narayanan and A Mauger, National Cancer Institute, National Institutes of Health, Bethesda, MD.

41 Cragg G, Suffness M. Metabolism of plant-derived anticancer agents. Pharmacol. Ther. 1988; 37 (3): 425-61.

42 Keller-Juslen C, Kuhn M, Stahelin H, von Wartburg A. Synthesis and antimitotic activity of glycosidic lignan derivatives related to podophyllotoxin. J. Med. Chem. 1971; 14 (10): 936-40.
43 O'Dwyer PJ, Alonso MT, Leyland-Jones B, Marsoni S. Teniposide: a review of 12 years of experience. Cancer Treat Rep. 1984; 68 (12): 1455-66.

44 Issell BF, Muggla FM, Carter SK, eds. Etoposide (VP-16): Current Status and New Developments. Orlando, FL: Academic Press, 1984.

45 Wang HK, Kuo YH, Schnur D, Bowen JP, Liu SY, Han FS, et al Antitumor agents 113. New $4 \beta$-arylamino derivatives of $4^{\prime}$ demethylepipodophyllotoxin and related compounds as potent inhibitors of human DNA topoisomerase II. J. Med. Chem. 1990; 33: 2660-6.

46 Personal communication. The primary pharmacological and pharmacokinetic data of GL331 were provided by Drs J Chen and W Choy of Genelabs Technologies, Redwood City, CA.

47 Wang HK, Morris-Natschke SL, Lee KH. Antitumor agents 170. Recent advances in the discovery and development of topoisomerase inhibitors as antitumor agents. Med. Res. Rev 1997; 17: 367-425.

48 Konoshima T, Takasaki M, Kozuka M, Tokuda H. Anti-tumor promoting activities of kampo prescriptions. II. Inhibitory effects of souseiryu-to on two-stage carcinogenesis of mouse skin tumors and mouse pulmonary tumors. Yakugaku Zasshi 1994; 114 (4): 248-56.

49 Takasaki M, Konoshima T, Yasuda I, Hamano T, Tokuda H. Inhibitory effects of shouseiryu-to on two-stage carcinogenesis. 2. Anti-tumor-promoting activities of lignans from Asiasarum heterotropoides var. mandshuricum. Biol. Pharm. Bull. 1997; 20: 776-80

50 Sheng J, Xu J, Yang J. Effect of breviscapin on plasma TXB2, 6keto-PGFa, and platelet aggregation in experimental acute myocardial ischemia. Chin. J. Cardiovasc. Dis. 1995; 23: 53-5.

51 Dong FX, Wei QA, Lin XH. Effects of di-ao-xin-xue-kong on coronary heart disease with left ventricular function and hemodynamics. Nat. Prod. Res. Dev. 1995; 7: 35-8.

52 Lin HW, Xu ZF, Zhao L. The kinetic effects on blood flow of su-xiao-jiu-xin-wan and jiu-sin-tau. Chin. J. Integr. Trad. Wes. Med. 1995; 15: 46-7.

53 Tanaka S, Tajima M, Tsukada M, Tabata M. A comparative study on anti-inflammatory activities of the enantiomers, shikonin and alkannin. J. Nat. Prod. 1986; 49 (3): 466-9.

54 Honda G, Sakakibara F, Yazaki K, Tabata M. Isolation of deoxyshikonin, an antidermatophytic principal from Lithospermum erythrorhizon cell cultures. J. Nat. Prod. 1988; 51 (1): $152-4$.

55 Konoshima T, Kozuka M, Tokuda H, Tanabe M. Anti-tumor promoting activities and inhibitory effects on Epstein-Barr virus activation of shi-un-kou and its constituents. Yakugaku Zasshi 1989; 109 (11): 843-6.

56 Sheehan MP, Atherton DJ. A controlled trial of traditional Chinese medicinal plants in widespread non-exudative atopic eczema. Br. J. Dermatol. 1992; 126 (2): 179-84.

57 Bensoussan A, Talley NJ, Hing M, Menzies R, Guo A, Ngu M. Treatment of irritable bowel syndrome with Chinese herbal medicine: a randomized controlled trial. JAMA 1998; 280 (18): 1585-9.

58 Stermitz FR, Lorenz PL, Tawara JN, Zenewicz LA, Lewis K. Synergy in a medicinal plant: antimicrobial action of berberine potentiated by $5^{\prime}$-methoxyhydnocarpin, a multidrug pump inhibitor. JNAS 2000; 97 (4): 1433-7. 